\title{
3.1 Laokoon in Outer Space? Towards a transformative hermeneutics of Art
}

\author{
Ulrike Landfester
}

When Alan Sokal, professor of physics in New York, in 1996 published an article entitled "Transgressing the Boundaries: Towards a Transformative Hermeneutics of Quantum Gravity" ${ }^{378}$ in the influential cultural theory journal Social Text, the journal's editors promoted its publication enthusiastically, taking it as a serious attempt by a representative of the so-called "hard sciences" to enter into a dialogue with the sciences on the other: side of the gap between the two cultures of knowledge which Charles P. Snow had so paradigmatically diagnosed in his famous 1959 "Rede Lecture". ${ }^{379}$ Instead of aiming at bridging the gap, Sokal's article was meant as a parody. It sharply denounced the - in the author's view infuriatingly incompetent efforts of humanities' scholars to colonialise the natural sciences while only succeeding to produce an incoherent mishmash of overblown pseudo-theoretical postmodernist terminology and misunderstood miscellaneous fragments of scientific facts. After the prompt unveiling of the article's parodist intention, a bitter battle ensued. On the one hand some earnestly advocated the necessity of enabling and using interdisciplinary synergies between "soft" and "hard sciences"; on the other side some, like Sokal, viewed the delimitation of disciplinary work as an imposition on the purity of science on the other, as Impostures intellectuelles, as Sokal-and his co-author Jean Bricmont put it in their subsequent book publication. ${ }^{380}$

By alluding to Sokal's 1996 parody in the subtitle of my own article, I take neither side in this quarrel but rather will try to follow up on the disciplinary transgression that Sokal performed: That his parody was not recognised as such by the editors of Social Text does not necessarily discredit their intellectual powers but rather points out that the inter- or trans-disciplinary work, that is already in progress has, in spite of such violent opposition, left its mark on contemporary discourse both in the humanities and social sciences and in the natural sciences. There is no doubt that Sokal is right when he attacks the promiscuous dilettantism that the post-humanist inter-disciplinarity movement has in some instances engendered; there are indeed some scholars who mistakenly believe their disciplinary training sufficient to cross over into any other scientific realms simply on the strength of their persuasion of the all-encompassing heuristic powers of cultural or social theory. At the same time, there is also no doubt whatsoever 
that scholars of disciplines even so far removed from each other like, for example, quantum physics and classical philology, can mutually greatly benefit from the other's expertise as long as they respect precisely those disciplinary differences which, in the end, must always remain the foundation of any productive dialogue.

Along those lines, the following article will apply the framework unwillingly suggested by Sokal in his use of the formula of "transformative hermeneutics" to an issue which, on first sight, is squarely based in a humanities' discipline - the theory of art - but which, on second sight, might very well at some stage in the future become relevant for the further improvement of space exploration technology. This issue is the possible development of the concept of Art under the conditions of human space travel and extraterrestrial settlements, that is to say, under conditions when humans leave their natural habitat on Earth either for a certain time span or even for good.

After a short introduction to the history of the concept of Art since the 18th century, three leading questions will be raised: $\mathrm{Can}$ Art be used to communicate with alien life forms? What, if any, impact might the physical differences between the environment on Earth and extraterrestrial environments, either space stations or other planets, have on human understanding and practicing of Art? Will Art and space technology remain separated by the gap between Snow's "Two Cultures" or is it conceivable that they might enter into a closer, mutually beneficial relationship?

\subsubsection{The space of Art: The Laokoon paradigm}

Before the imaging technologies of the 20th century started to delimit Art - with a capital A, to mark the term's conceptual dimension - towards the currently rather all-encompassing concept of Media, the space of Art in social and cultural theory was defined by the emergence of aesthetics out of two major historical paradigm changes.

The first of these changes took place in the early modernity during the 15 th and 16th century, when the improvement in reproduction techniques both for images and texts - effective woodcut and copperplate technology and the newly-invented printing press - on the one hand, and the Reformation's iconoclast movement on the other, converged towards setting Art free from the fetters of its hitherto mainly religious function. From then on, the use of both images and texts was no longer confined within the boundaries of affirmative action towards Christianity as propagated by the Church. Instead, apart from becoming an important instrument in the distribution of scientific and other secular forms of knowledge. Art began to 
gain a certain independence, documented by and promoted through an increased theoretical interest in its specific merits, which had been in abeyance since the works of Aristoteles had first drawn attention to them. ${ }^{381}$

The second change came about not long after, during the 18th century, when philosophers like Alexander Baumgarten in his "Aesthetica in nuce" (1750/59) began to draw the conceptual consequences already implicitly laid out in the Renaissance theory of Art: Baumgarten was among the first who argued that beauty, in the sense of the sensual satisfaction a work of art gave to its recipient, must be conceived of as a value of its own, independent from any instrumental use for societal, political, religious or economic purposes, a value, moreover, which in itself constituted a sufficient reason both for the creation and the reception of Art.

Shortly after Baumgarten's "Aesthetica in nuce" had appeared, Gotthold Ephraim Lessing published a treatise which subsequently became one of the founding documents of the modern'concept of Art: "Laokoon: oder über die Grenzen der Mablerey und Poesie" (translated: Laokoon: or on the limits of poetry and painting). ${ }^{382}$ Through the choice of his main title Lessing already alluded to an important part of the argument he was going to present in his treatise, i.e. that as Christianity in its use of both textual and iconic artefacts had not developed any pertinent concept of Art, the foundations of such a concept must be drawn from the artwork of Greek antiquity to be built upon according to the needs of modernity.

The name of Laokoon means both the mythical protagonist featured in antique renderings of the history of the siege of Troy and a famous marble statue representing him and his sons. According to the myth, the priest Laokoon had warned the people of Troy not to take the wooden horse, which the Greeks had offered to them as a present, into the city. Laokoon, it turned out, was right, as the wooden horse contained armed soldiers who the night after the gift had been taken in proceeded to vanquish the city from within. The Trojans, however, would not listen to his warnings, especially as Athene, seeing her scheme for the conquest of Troy endangered by him, sent out two huge sea snakes to kill the priest's two sons and subsequently also the father when he tried to rescue them. Taking up this myth, around 200 B.C. three stone masons from Rhodos created a marble statue depicting Laokoon and his sons desperately fighting against those snakes; the original is lost, but it had been copied several times around 100 b.C., and in the 16 th century one of those copies turned up in Rome. Housed today in the Vatican Museum (cf. Figure 1), during the 18th century plaster copies of this statue were circulated through Europe, inspiring enormous interest and thus, among several others, Lessing's treatise on the nature of Art.

In this treatise, Lessing took Baumgarten's idea on the independent value of aesthetics a significant step further by applying it to create an epistemological 


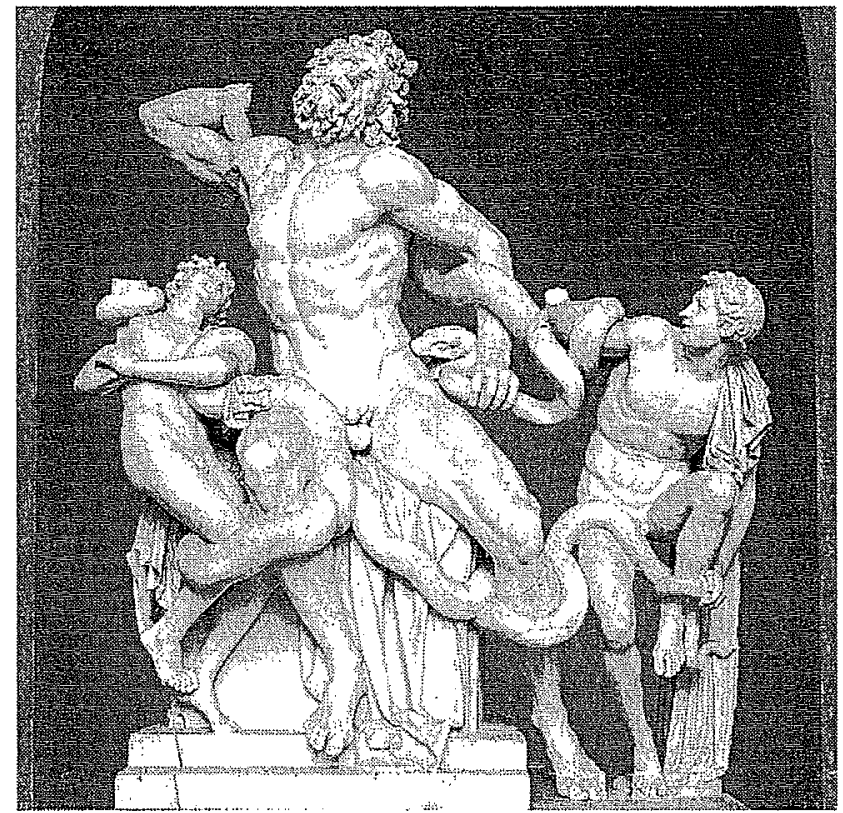

Fig. 1. Laokoon, anon. copy, ca. 100 B.C., Rome, Vatican Museum (source: "Vatikan." Web Es. 16 Aug. 2010. bttp://wrww.web-es.eu/rom/kirchen-vatikan/sankt-peter-petersdom).

framework, that allowed distinctions to be made between different types of Art, giving a set of criteria which, on the whole, served to systematically establish the aesthetic autonomy of Art. By contrasting painting - as a label for iconic representation including statues like the one he uses as his crucial point of reference - and poetry, he stipulates that while poetry may describe Laokoon and his sons screaming aloud with pain and fear, any iconic representation of the same subject had to abstain from showing the three figures with open mouths, because this would -create a visual effect both ridiculous and disgusting. The stonemason therefore has to translate their pain and fear into an appropriately expressive body language with twisted limbs and bulging muscles, which in turn cannot be reproduced by poetry convincingly.

While Lessing's interpretation of the different impressions produced by painting and poetry in themselves of course are influenced strongly by 18th century ideas on what is or is not appropriate and/or beautiful and thus, from today's point of view, certainly may seem rather questionable, there still remains the fact that he for the first time diagnosed a feature which until the 20th century has proved a key element in any conceptual debates on Art: aesthetic value is created neither by the choice of subject nor by the choice of technique alone, but by the dialectical adaptation of one to the other. There is no privileged dominion of the instrument of expression over the issue expressed by it or vice versa, as is the case in any communication process outside the realm of Art. Instead, the aesthetic value of a piece of Art is constituted by the relation between the techniques used and its subject. 


\subsubsection{Anthropomorphism revisited: The alienness of Art}

The question whether Art could be used to communicate with alien life forms, i.e. whether the concept of Art is bound so closely to humanity that it cannot be supposed to be comprehended by any other species on however abstract a level, ${ }^{383}$ or whether there are any indicators that exactly because of its intrinsically human quality Art might yield some potential in that area, seems fairly self-answering: as we know nothing about what to expect, should we ever indeed meet with any extraterrestrial life-forms, except the fact that they are unlikely to exhibit any similarity to our species at all, we must presume that our concept of Art will be as alien to them as any of their modes of expression will be to us. ${ }^{384}$ Still, the question is not quite as superfluous as it may seem at the first glance, as there are three aspects to it, which might still bear some consideration:

(1) Even if other life forms might not be able to relate to any kind or form or content in examples of our kind of Art, they might still recognise it on the whole as a sign of an advanced species;

(2) History has proven that in the process of exchange following an encounter between strange civilizations, artefacts circulating from one civilisation into the other often gain Art status through their sheer alterity, thus promoting a basic exchange of however superficial elements of knowledge about the other;

(3) Art with its experimental and speculative propensities has already been and will in the future be a useful heuristic instrument for developing an awareness of the probable non-anthropomorphous "alterity", i.e. otherness, of alien life forms.

The first aspect pertains to a structurally economics point of view. Since Art has been released into aesthetic autonomy through the paradigm changes described above, its very existence denotes a sphere of cultural activity which until today, spoken utilitaristically, is usually taken as superfluous: music and paintings, statues and ornamental gardens, literary texts and theatre performances neither feed nor clothe nor heal, nor can they be used as weapons or agricultural instruments. Their function is "merely" one of cultural self-identification and has been so even before the age of aesthetics, given that any pre-aesthetic religious artwork might seem to an alien life form equally unnecessary in the strict pragmatic sense of instruments to be used for the preservation of life. While the meaning of such luxuries can certainly not be expected to be evident to extraterrestrial species, there might still be the slight chance that the mere fact that humanity is able to afford them, could act as an indicator of a high civilisationally developed stage, thereby identifying the 
species which inhabits Earth as one which just might be worth to be taken into account. This argument is, of course, extremely speculative and, moreover, in a way guilty of exactly that kind of anthropomorphism which my former remarks have denounced as futile - but nevertheless it derives a certain kind of value $e x$ negativo: Assumed that it is quite sure that Art as such is non-communicable to non-human species, the luxury meta-angle might well be the only conceivable way of using it in communication at all.

The second aspect of the question has no direct relevance for active communication purposes but instead concerns the possibilities of what might happen in the realm of Art after an inter-species encounter. As Luca Codignola has pointed out, the most significant of encounters in the history of humankind, the discovery of America with its subsequent process of trafficking between Europeans and Indians, has clearly shown both the dangers to be avoided and the strengths to be relied on for future encounters. ${ }^{385}$ "While Codignola mainly stressed the ideological and biological lessons to be learnt from the American encounter, it also had the by-effect of introducing artefacts to Europe. While these usually fulfilled religious or pragmatic functions in their culture of provenance, once in Europe they were incorporated into the field of Art, losing their dependence on a functional context and instead gaining the status of aesthetic autonomy. In the 18th and 19th century such items not only became proudly displayed collectors' items but also inspired European Art into assimilating characteristic forms as well as strange techniques. On that level, at least on the human side of any possible future encounter, the concept of Art might again well prove a transformational platform for integrating knowledge about the non-human other into the human self.

The third aspect of the use of Art in dealing with extraterrestrial life forms is probably the most fruitful for space exploration, seeing that its application has quite a long and productive history. Cardinal Nikolaus Cusanus for example, a 15 th century philosopher and advisor to the pope, in his treatise "De docta ignorantia" (1440) came to the conclusion that not only was it highly probable that the planet Earth was not, in fact, the center of the universe but also that it was equally probable the other planets might be inhabited by "other species"386 who were not remotely human. Johannes Kepler in his playfully fictional dreamnarrative "Somnizum" (1634) already imagined a whole lunar civilisation of nonhuman creatures. Even if Cusanus, Kepler and others of their time who thought along similar lines ${ }^{387}$ did not see themselves as artists but rather as scientists, they still employed the freedom of speculative fiction. In the 18th century this freedom of speculative fiction was turned over into the realm of Art as a means for creating scenarios in which humans had to come to terms with categorically non-human alterity, scenarios which in their basic assumption of such alterity anticipated much 
of what Stanislaw Lem 1961 in his novel "Solaris" established as the leading topic of this most classic of science fiction classics. It is anything but a coincidence that Lem in his novel gave the spaceship that first discovered the planet Solaris the name of Laokoon - which served not only to emphasise the fact that Lem counted his novel as a work of Art, but also pointed to the paradigm of alterity inherent in Lessing's modern conceptualisation of Art: According to Lem's reading of Lessing's treatise, being constitutionally structured by insurmountable differences between poetic and iconic techniques of presentation, Art is uniquely equipped to make insurmountable differences between life forms a subject of heuristic exploration.

\subsubsection{Unearthing Art: The "environment factor"}

Art is not merely a conceptual entity. To the contrary, its conceptualisation is a meta-construction built on and derived from its material manifestations, which in turn are evidently hugely influenced by the concrete environment from which and in which they are brought forth. This begs the question of how far and in what ways the concept of Art might change in reaction to environments which are physically different from the planet Earth, i.e. the environments of space ships, space stations or even settlements on other planets.

Looking at what is currently available on the internet in terms of Art related to outer space, it quickly becomes clear that of course visual Art has long since opened up towards inspirations from that particular source - more so perhaps even than 20th century literature, seeing that space exploration from the beginning has communicated its findings mostly in images to the broader public. A typical example of the spin-offs of space exploration in that respect is "The Cosmic Cafe" with its "Outer Space Art Gallery", the latter featuring mainly the works of spray painter g.HARLAN whose fantastic renderings of cosmic landscapes are wonderfully colourful and nicely executed - but remain safely in the realm of earthly materiality in terms of format and technique.

Quite another and much more interesting example, however, is a project that is embedded in something of a work of art itself: "Spacearts". ${ }^{388}$ The framework is a huge endeavour, an internet archive aiming to comprise all works of art concerned with outer space since the middle of the 19th century carried by the International Academy of Astronautics (IAA), the European Space Agency (ESA), the International Association of Astronomical Artists (IAAA), the London-based art and science agency Arts Catalyst, the Institute for Unstable Media, Rotterdam (V2), MIR, an international consortium of institutions having space art activities 


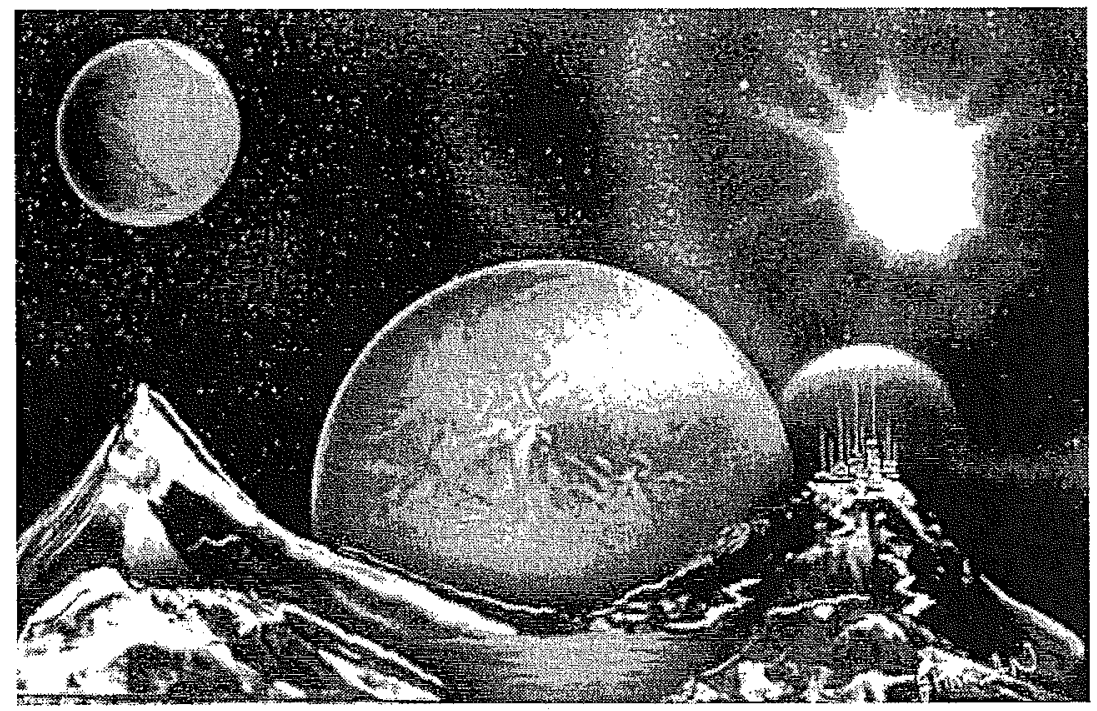

Fig. 2. ReddishMoon Rising (source: g. HLARLAN. Cosmic Cafe and Outer Space Art Gallery. 27 Jan. 2010. bttp://www.outer-space-art-gallery.com/space-artist.btml).

including Leonardo/Olats, Projekt Atol (Slovenia) and the TV Gallery (Russia) and the Maison d'Ailleurs - Museum of Science Fiction, Yverdon. Spacearts' selfdescription puts forward precisely the heuristical argument, that I have made above.

Artists have been at the forefront of space exploration since its very beginning. Their works of imagination have stimulated and catalysed a new human endeavour. Works of art and literature about space have both anticipated and stimulated space development, while exploring destinations and technological concepts that were often too dangerous, too distant or too advanced for the science and technology of the moment. ${ }^{389}$

Spacearts currently displays 23 projects, among them "The Mars Patent", an interactive web project run from Hamburg in Germany by Claudia Reiche, and Helene von Oldenburg. The Mars. Patent self-describes itself as "[t]he first interplanetarian Exhibition Space on Mars":

"THE MARS PATENT is a place for art and theory and sensible to its various concepts. THE MARS PATENT will exhibit projects, considering the special situation of the Mars Exhibition Site, e.g. geographic, geologic and meteorological aspects. THE MARS PATENT offers a suitable positioning for sculptures, internet relay chats, kinetic objects, art- and mediatheories, science fiction literature, videos, sound installations, manifestos, web-art etc. (You could even try it with paintings, but please send digitized formats. Remember: There are no walls on Mars!) $)^{390}$

The introductory page of the exhibition space shows a map of a part of the surface of Mars (cf. Figure 3), where the exhibition is supposed to be located between "the 


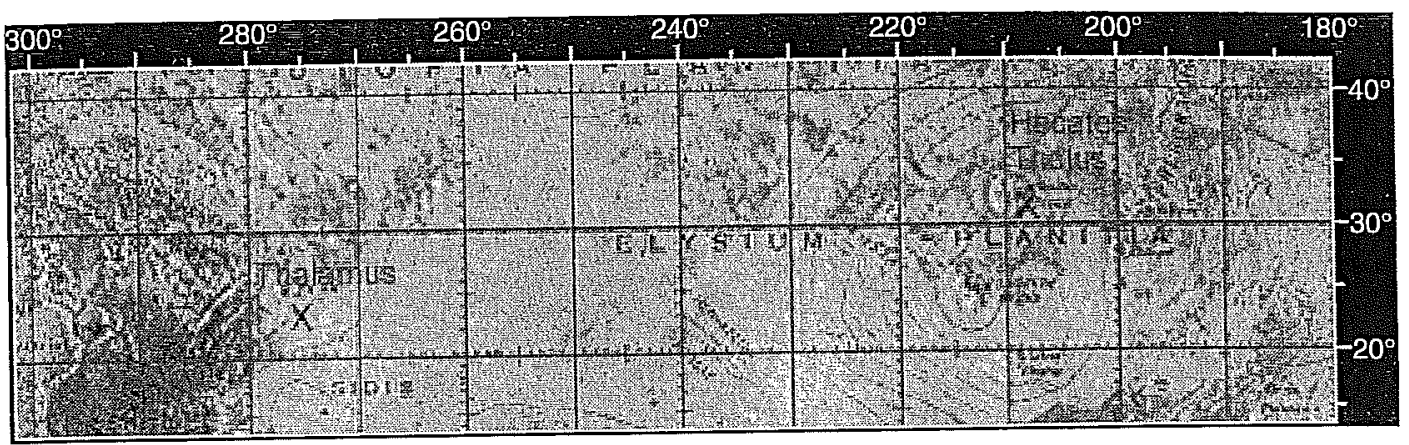

Fig. 3. The Mars Patent (source: Reiche, Claudia, and Helene von Oldenburg. "The Mars Patent." The Mars Patent. 27 Jan. 2010 http://www. mars-patent.org/mes/mes.htm).

steep volcanic mountain Hecates Tholus and the bizarre Thalamus region". 391 The map, together with information about the weather and chemical and geological data, offers a sense of material accessibility, which in the light of the factual inaccessibility of the area in question, underlines and heightens the purpose of the project. The conceptual impetus of Reiche, and von Oldenburg aims at forcing the spectator to accept certain conditions of perception: it is solely the spectator's eye which provides the interface between Space and Art, an interface connecting two things which are virtually not there - or rather are there only virtually, as the works of art which are to be exhibited. Thus, Reiche, and von Oldenburg simulate a future of Art where the materiality of artefacts will progressively lose - in fact, is already losing - its ground to the immateriality of digitally generated and transmitted images. Works of Art will then no longer be things from canvas and colour, stone or any other earthly substance but will consist instead of pixels and electronic impulses, gaining their reality solely through the visual perception of the spectator without any need for them to have a physically tangible existence - a state of Art which, however counterintuitive this may seem at first glance, will certainly reaffirm Lessing's notion of the necessary dialectical interplay between technique and subject matter under the conditions of the space age.

\subsection{4 "Theatre level": Art and space technology}

Thus, already through this "environment factor", Art is closely linked to space technology, both in terms of the inspiration derived from and the instrumental use of its achievements. There is, however, yet another angle to their relationship which even more directly pertains to the transformative hermeneutics paradigm. The first half of the title for this last part of my article is taken from an article by 
Xavier Pasco on "Controlling the freedom of using space: The White House Policy dilemma" which dedicates a paragraph to 'theatre level' of 'force multiplier' space (1991-2007): adapting the space systems to the new strategic environment". ${ }^{392}$ Pasco maintains that during this phase in the emergence of American space policy, space was conceived, on the one hand, as "the cornerstone of future defence architectures around which forces and doctrines would have to organise", ${ }^{393}$ focussing, theatre-like, the perspective of the spectator solely on the military potential while, on the other hand,

"space should also appear as one of the most flexible sectors of activity given its recent history, an a priori less heavily entrenched area than other military domains supposedly more heavily structured", 394

thus open for combined or force-multiplying use by military and civilian stakeholders alike.

Though not spelled out by Pasco, and quite probabily not even intended that way, his use of the term "theatre level" implies the awareness that the human use of space has a heavily theatrical dimension. On the face of it, this dimension is constituted by the fact that space exploration has always, at least in the public eye, manifested itself in the shape of avidly watched transmissions of images - which is one of the poetological foundations of the above-mentioned "Mars Patent" -, and it is to be supposed that the "theatre-level" of American defence activities in space at least in part means a pronounced display of military power towards potentially threatening other nations. More important, however, is the theatricality of the transmitted images themselves which is, of course, inherent in any image but which gains in significance when the images in question show things which in reality cannot - at least not yet - be seen by human eyes like; for example, the surface of Mars. Stimulated by the knowledge that for several decades perfectly convincing photo-like images have been generated digitally, so that what is sold to the spectator as an iconic re-presentation may in fact be an artefact with no relation whatsoever to any given reality. Doubts as to the validity of images from outer space have begun to undermine the average spectator's faith in their documentary character ever since, after the first landing of humans on the Moon in 1969, rumours began to circulate that the whole event had been an elaborately staged visual hoax.

As the fabrication of images without a direct object of mimetic reference is probably as old as mankind itself, there is no need whatsoever to broadly denounce the whole technology of visual communication as untrustworthy devil's work. Seeing, however, that especially in the area of space exploration, in both military and civilian operations in space and at some none-too-far future stage also in interplanetary exchange, this technology plays a crucial enabling role, it may be as 
well to meet head on possible problems in connection with'the theatricality aspect instead of ignoring them altogether on the strength of the assumption that any truly scientific mind will always know exactly what can and what cannot be seen. Here, Art may serve the purpose of acting as a catalyst for critical reflection on both the dangers and the possibilities inherent in the circulation of images, ${ }^{395}$ developing strategies for coping with the one and optimising the other - for example by experimentally opening up avenues towards getting rid of the moralist notion of simulacra being a priori lies, and instead propagating the sheer rationality of transmitting information encoded in images without any need for those images' mimetic anchorage in reality. Thus, interpreting space technology through Art might at least partly succeed where the mythical Laokoon fatally failed, warning humankind against the dangers lurking on the "theatre-level" of the Trojan horse of visual communication in outer space.

${ }^{378}$ Sokal, Alan. "Transgressing the Boundaries: Towards a Transformative Hermeneutics of Quantum Gravity." Social Text 46/47 (1996): 217-52. University of New York, Faculty of Physics 21 Sep. 2010. http://www.physics.nyu.edu/faculty/soka1/transgress_v2/transgress_v2_singlefile.html.

${ }^{379}$ Snow, Charles P. (ed.) "The Two Cultures. The Rede Lecture." The Two Cultures. Cambridge: Cambridge University Press, 1998: 1-52.

${ }^{380}$ Sokal, Alan, and Jean Bricmont. Impostures Intellectuelles. Paris: Odile Jacob, 1997. For a resume of the above-mentioned conflict see Herbrechter, Stefan. Posthumanismus. Eine kritische Einfuihrung. Darmstadt: Wissenschaftliche Buchgesellsschaft, 2009: $129 f$.

: 381 cf. Belting, Hans. Bild und Kult. Eine Geschichte des Bildes vor dem Zeitalter der Kunst. München: Beck, 1990: 510-45.

${ }^{382}$ Lessing, Gotthold Ephraim. Laokoon: oder über die Grenzen der Mahlerey und Poesie. Berlin: Christian Friedrich Voss, 1766. Laocoon: or, The limits of Poetry and Painting, translated by William Ross. London: Ridgeway, 1836.

${ }^{383}$ An argument which would follow from the ideas put forward by Belting, Hans. Bild-Anthropologie. München: Fink, 2001.

${ }^{384}$ Dunér, David. "Astrocognition: Prolegomena to a Future Cognitive History of Exploration." (in this volume) suggests that such a comparative analysis will shed light on the specific or typical characteristics of our species.

${ }^{385}$ Codignola, Luca. "Future Encounters: Learning from the past?" Humans in Outer Space Interdisciplinary Odysseys. Eds. Luca Codignola and Kai-Uwe Schrogl. Vienna: SpringerWienNew York, 2009: 14-21.

${ }^{386}$ Kues, Nikolaus von. De docta ignorantia. Die belehrte Unwissenheit, vol. 2. Hamburg: Meiner, 1967. 101. translated by the author.

${ }^{387}$ Cf. Heuser, Marie-Luise. "Transterrestrik in der Renaissance. Nikolaus von Kues, Giordano Bruno, Johannes Kepler." Von Menschen und Ausserirdischen. Eds. Michael Schetsche, and Klaus Engelbrecht. Bielefeld: transcript, 2008: 55-80. 
388 "Spacearts - Die Space Art Datenbank." Spacearts. 21 Jan. 2010. http://www.spacearts.info.
${ }^{389}$ Ibid.

390 "The First Interplanetarian Exhibition Space on Mars." Mars Patent. 21. Jan 2010. http://www. mars-patent.org.

${ }^{391}$ Reiche, Claudia, and Helene von Oldenburg. "The Mars Patent." The Mars Patent. 27 Jan. 2010. http://www.mars-patent.org/mes/mes.htm.

${ }^{392}$ Pasco, Xavier. "Controlling the Freedom of Using Space: The White House Policy Dilemma." Yearbook on Space Policy 2006/2007: New Impetus for Europe. Eds. Kai-Uwe Schrogl, Charlotte Matthieu, and Nicolas Peter. Vienna: SpringerWienNewYork, 2008: 197-210. 199.

${ }^{393}$ Ibid. $199 f$.

${ }^{394}$ Ibid. $199 f$.

${ }^{395}$ The same of course goes for texts, cf. Landfester, Ulrike. "Missing the Impossible: How We Talk and Write about Space. Humans in Outer Space - Interdisciplinary Odysseys." Eds. Luca Codignola and Kai-Uwe Schrog1. Vienna: SpringerWienNewYork, 2009: 94-106. 